\title{
Recibir la reparación. Aproximación a dos organizaciones de desplazados del conflicto armado interno en Lima y su acceso a reparaciones colectivas
}

\author{
Ivan Andres Ramírez Zapata \\ Universidad de Los Andes, Bogotá \\ ia.ramirez@uniandes.edu.co
}

RESUMEN

Este articulo muestra las características de dos organizaciones de desplazados (residentes en Lima) por el conflicto armado interno peruano (1980-2000) y la manera en que tales características conforman oportunidades y obstáculos de cara al acceso al Programa de Reparaciones Colectivas - contemplado dentro de la politica de reparaciones del Estado peruano-, el cual entrega a un beneficiario colectivo un proyecto para su aprovechamiento económico o para la reconstrucción social/institucional del grupo. Sobre la base de revisión bibliográfica, entrevistas a miembros de estas organizaciones y trabajo de campo etnográfico, se argumenta que las características de cada organización - junto con el tipo de proyecto de reparación colectiva escogido - crean escenarios de retos y posibilidades cuya resolución requiere capacidades de acción colectiva con las que estas organizaciones no necesariamente cuentan, lo que, en los hechos, menoscaba su derecho a la reparación. De esta manera, se afirma la importancia no solo de evaluar la oferta de reparaciones y su calidad, sino también las características de la demanda, es decir, de los grupos de desplazados beneficiarios y sus interacciones internas, y cómo estas se relacionan con el acceso a dichas reparaciones.

Palabras clave: conflicto armado interno, desplazamiento interno, Perú, reparación colectiva, acción colectiva. 


\section{Receiving a reparation. Two organizations of internally displaced persons in Lima (Peru) by armed conflict and their access to collective reparations}

\section{ABSTRACT}

This article illustrates the characteristics of two Lima-based organizations of persons displaced by the internal armed conflict in Peru (1980-2000), and the way in which these characteristics create opportunities and obstacles for access to the Program of Collective Reparations - a key element of the Peruvian reparations policy - This program provides funding to a collective beneficiary for institutional strengthening or economic entrepreneurship. Based on bibliographic review, interviews with members of these organizations as well as ethnographic field work, I show that the characteristics of each displaced persons' organization together with the type of collective project they choose create scenarios of challenges and possibilities which pose difficulties to these groups, requiring collective action capacities which they do not necessarily have. This results in a de facto situation that undermines their right to reparation. Therefore, I argue the importance not only of analizing the reparations offer and its quality, but also the characteristics of the demand, that is, of the beneficiary groups of displaced persons and their internal interactions, and how these factors shape access to reparations.

Keywords: internal armed conflict, internally displaced persons, Lima, collective reparations, collective action. 


\section{INTRODUCCIÓN ${ }^{1}$}

El desplazamiento interno a causa del período de violencia armada en el Perú (1980-2000) rara vez ha sido parte de las preocupaciones centrales de los académicos que investigan temas de conflicto armado y posconflicto en el país. Así, en el estado de la cuestión que hiciera Carlos Iván Degregori sobre las investigaciones en esta materia - en el primer tomo de sus obras completas - no hay mención alguna a publicaciones sobre desplazamiento (Degregori, 2011). Un balance más reciente (Salazar Borja, 2015) revisa investigaciones desde el punto de vista de los estudios sobre memoria e incluye tres referencias a textos sobre desplazados, ninguno de los cuales es reseñado o comentado por el autor. La propia Comisión de la Verdad y Reconciliación (CVR) peruana no tocó el tema con la misma profundidad con la que trató casos de homicidios, torturas o desapariciones, probablemente debido a que estas afectaciones ${ }^{2}$ constituyen las preocupaciones tradicionales en las miradas sobre violaciones a los derechos humanos, no así el desplazamiento (Barrantes, 2012).

El presente artículo pretende aportar a la reflexión y conocimiento sobre la población desplazada durante el período $1980-2000$ y, más específicamente, sobre aquel segmento de desplazados internos que no regresaron a los lugares en los que residían al momento de estallar el conflicto. Asimismo, este trabajo refiere al desplazamiento no en relación con el contexto de conflicto armado, sino respecto del momento actual, es decir, en el marco de retos, preocupaciones y deudas pendientes que existen hoy en relación con los legados de la violencia armada. Específicamente, me pregunto por el acceso de organizaciones de desplazados a un componente de la política estatal de reparaciones, a saber, el Programa de

Una primera versión de este texto fue leída en el XXXIV International Congress of the Latin American Studies Association (Nueva York, 27-30 de mayo del 2016), donde fue comentada por Jelke Boesten. Posteriormente, recibió observaciones de Rogelio Scott, Joe Feldman y Raquel Pérez, a quienes agradezco por ello.

2 El término «afectaciones» alude a los distintos tipos de daño y perjuicio cometidos contra la población durante el conflicto armado. 
Reparaciones Colectivas, que contempla la ejecución de un proyecto en favor de una organización de desplazados que puede perseguir objetivos tan diversos como apoyo al saneamiento físico legal, capacitación en derechos humanos, ampliación de infraestructura y servicios básicos o proyectos productivos y de comercio, entre otros. Así, pretendo contribuir no solo a la discusión académica sobre desplazamiento, sino también a la reflexión respecto de los alcances y límites de la política estatal de reparaciones en el escenario posconflicto nacional.

Este texto se basa en material recogido durante jornadas de trabajo de campo con organizaciones de personas desplazadas en la ciudad de Lima entre los años 2014 y 2016, así como en la revisión de la bibliografía principal sobre desplazamiento y reparaciones en Perú. Se trata, en particular, de la experiencia de dos grupos de personas desplazadas organizadas en los distritos de Ate y Lurigancho - Chosica, que se encuentran reclamando atención y reparación al Estado. Se trata, asimismo, de la primera aproximación etnográfica al acceso a reparaciones por grupos de desplazados, y a las reparaciones colectivas en particular.

El siguiente segmento expone las principales características del desplazamiento interno durante el conflicto armado en el Perú y describe las políticas existentes hoy en día para atender a las personas consideradas «afectadas» o «víctimas» de este período, en especial las que se dirigen a desplazados internos. El tercer segmento resume los antecedentes bibliográficos más relevantes para efectos de esta investigación. Los apartados cuarto y quinto describen y analizan las características de las dos organizaciones referidas y la relación que guardan con el acceso a reparaciones colectivas. El texto culmina con las conclusiones.

\section{DESPLAZAMIENTO INTERNO POR CONFLICTO ARMADO EN EL PERÚ Y ESCENARIO POSTERIOR}

El Perú vivió un período de violencia armada en el último tramo del siglo XX. La CVR peruana ${ }^{3}$ caracterizó dicho período como uno de «conflicto armado interno» y estimó que este tuvo lugar entre los años 1980 y 2000. Asimismo, proyectó una cifra de 69280 víctimas mortales como resultado de dicho proceso, además de ratificar el cálculo ya conocido por ese entonces de más de medio millón de personas que habrían tenido que migrar forzosamente. Con migración forzosa o desplazamiento interno me refiero a las:

La CVR peruana se creó en junio de 2001 y entregó su Informe final el 28 de agosto de 2003. 
[...] personas o grupos de personas que se han visto forzadas $u$ obligadas a escapar o huir de su hogar de residencia habitual, en particular como resultado o para evitar los efectos de un conflicto armado, situaciones de violencia generalizada, de violaciones de los derechos humanos o de catástrofes naturales o provocadas por el ser humano, y que no han cruzado una frontera estatal internacionalmente reconocida (Oficina de Coordinación de Asuntos Humanitarios de las Naciones Unidas, 2010 [1998], p. 12).

Los números que existen sobre desplazamiento interno deben ser tomados con pinzas, pues es difícil establecer su grado de confiabilidad. Mientras que la cifra que goza de mayor consenso señala que 600000 personas se desplazaron en el período referido (Mendoza, 2000), la especialista que propuso dicha estimación sostiene que, por razones metodológicas, no es una cifra confiable y cree que los desplazados habrían sido alrededor de un millón ${ }^{4}$. Se han observado vacíos y problemas presentes en el registro oficial de desplazados por el conflicto armado en el Perú (Ramírez Zapata, 2018), los cuales son correlato de las dificultades técnicas identificadas por la experiencia internacional y que hacen del conteo riguroso de este tipo de población una labor complicada (Internal Displacement Monitoring Centre, 2018, pp. 72-81; United Nations High Commissioner for Refugees, 2015). No obstante, más allá de cualquier discusión que pueda tenerse sobre el carácter de estas cifras, no hay mayores dudas respecto de que se trató de un fenómeno masivo.

En 1993, en el marco de una corriente internacional en favor de establecer los derechos de las personas desplazadas y las obligaciones estatales para con ellas (Cohen y Deng, 2008), el Estado peruano creó el Programa de Apoyo al Repoblamiento y Desarrollo de Zonas de Emergencia (PAR), que constituyó durante diez años la única política estatal específica sobre desplazamiento. El trabajo de esta entidad se orientó a promover el «retorno», esto es, el regreso de las poblaciones desplazadas a sus lugares de residencia originales y a apoyar su reconstrucción. Las pocas evaluaciones en la materia señalan que, en última instancia, la experiencia del PAR fracasó: habría atendido solo al 10\% de la población que necesitaba ayuda (Francke, Castro, Francke y Espino, 2001) y muchos de los que así retornaron «abandonaron [posteriormente] el campo debido a múltiples razones» (Revollar Añaños, 2001, pp. 20-21).

\footnotetext{
Entrevista a Isabel Coral (17 de abril de 2015).

Para estas evaluaciones, el PAR fracasó en relación con sus objetivos, es decir, alcanzó solo a una proporción reducida de desplazados y no logró que estos fijaran su residencia territorial en sus comunidades. Esta perspectiva ha sido criticada por Stepputat y Sørensen (2001), quienes
} 
El PAR pasó por diversas etapas hasta que desapareció y fue reemplazado por una oficina derivada de una nueva normativa sobre el tema. En efecto, en el año 2004 se emitió la Ley 28223, Ley sobre los Desplazamientos Internos, que tiene por objeto reconocer la naturaleza legal del estatuto específico de «desplazado» y definir sus derechos y garantías durante los distintos momentos del desplazamiento. Según esta ley, el Ministerio de la Mujer y Desarrollo Social ${ }^{6}$ es el ente rector encargado de los desplazados en el Perú, tarea que hoy ejerce a través de la Dirección de Desplazados y Cultura de Paz ${ }^{7}$. Esta ley reconoce y ampara a quienes se desplazan a causa de proyectos de desarrollo, desastres naturales o ecológicos, políticas de coerción y conflicto armado interno o internacional.

En el año 2005 apareció una segunda ley relevante. Se trata de la Ley 28592, que crea el Plan Integral de Reparaciones (PIR), cuyo reglamento, emitido en el 2006, afirma que el objetivo de la reparación es «permitir su acceso [de las personas afectadas] a la justicia, la restitución de sus derechos, la resolución de las secuelas derivadas de las violaciones a los derechos humanos y la reparación material y moral, específica o simbólica, por lo daños sufridos», para lograr el «restablecimiento y plena vigencia de los derechos así como de las condiciones, recursos, capacidades, oportunidades y calidad de vida perdidos por efecto del proceso de violencia y sus secuelas» (Ministerio de la Mujer y Desarrollo Social, 2010, p. 77).

Tienen derecho a ser reparadas todas las personas que la ley considera víctimas del conflicto. Estas se dividen en víctimas directas — que incluyen a las personas desplazadas ${ }^{8}$ - e indirectas ${ }^{9}$, y se les considera beneficiarios indivi-

cuestionan que la categoría «desplazado» en el Perú asuma que la gente vive en un único lugar de forma estable. Para los autores, ello ignora que la historia peruana previa al conflicto armado se caracteriza por constantes movimientos migratorios de temporalidad variables y con fines diversos, en donde la constricción espacial es una desventaja; desde su punto de vista, la permanencia territorial no puede ser un objetivo para un programa de reconstrucción de comunidades rurales porque no se corresponde con la experiencia histórica de los sujetos beneficiarios.

6 Que en enero de 2012 cambió de nombre a Ministerio de la Mujer y Poblaciones Vulnerables (MIMP).

7 Que a partir de ahora será referida como «Dirección de Desplazados».

8 Otros tipos de víctimas directas son: personas fallecidas, personas desaparecidas, familiares de personas desaparecidas, miembros de las fuerzas del orden, integrantes de comités de autodefensa y autoridades civiles heridas o lesionadas, personas objeto de tortura, personas objeto de lesiones graves, personas objeto de violencia sexual y personas que sufrieron formas de violencia sexual distintas de la violación.

9 Hijos producto de una violación sexual, personas menores de edad que conformaron un comité de autodefensa, personas indebidamente requisitoriadas por terrorismo o traición a la patria y personas que quedaron indocumentadas. 
duales. La calificación como víctima individual conlleva un proceso de registro que culmina en su inscripción en el Libro 1 del RUV, que es la base de datos de beneficiarios individuales. Existe también el registro de beneficiarios colectivos, que corresponde a dos tipos: a) grupos de desplazados que no retornaron a sus lugares de origen, $\mathrm{y} b$ ) comunidades campesinas, comunidades nativas y centros poblados cuya estructura material y social quedó dañada. El proceso de registro de beneficiarios colectivos culmina con la inscripción en el Libro 2 del RUV.

Este marco legal crea, además, siete programas de reparación —entre ellos, el Programa de Reparaciones Colectivas-, que junto una serie de reglamentos y procedimientos constituyen la «oferta» estatal de atención y reparación. Este texto, sin embargo, se enfoca en la «demanda», es decir, en la acción de grupos de personas desplazadas que exigen reparaciones y sus iniciativas para acceder a ellas. La siguiente sección resume las ideas académicas que encuadran este interés y presenta la descripción del escenario que contextualiza el trabajo de campo.

\section{DESPLAZADOS: CIUDADES, ORGANIZACIONES, REPARACIONES}

El grueso de publicaciones sobre desplazamiento interno en el Perú tiene un fuerte componente de diagnóstico: contiene cifras, datos y un resumen de los principales problemas de la población desplazada. Estos textos subrayan que se trata de un sector conformado por grupos históricamente excluidos, inmersos en problemas persistentes como pobreza, bajo nivel educativo y servicios básicos deficientes, a los cuales se superpuso la violencia armada (Asociación de Familias Desplazadas en Lima, 2009; Comisión de la Verdad y Reconciliación, 2003, p. 654).

Desde esta perspectiva, se destaca que el proceso de desplazamiento supuso un episodio traumático marcado por el miedo y la violencia, lo que empeoró las condiciones sociales, económicas y de salud de la población desplazada (Coral, 1994). Para el caso de los desplazados en ciudades, y en Lima en particular, se ha identificado que la calificación laboral fue uno de los problemas más acuciantes - en tanto que sus conocimientos correspondían a tradiciones agrícolas y ganadera- (Mendoza, 2000), y que la demanda de mayor acceso a educación ha sido una de las más persistentes (Diez Hurtado, 2003). Asimismo, el asentamiento de los desplazados en la ciudad capital se dio sobre todo en los pueblos jóvenes y asentamientos humanos, caracterizados por una precaria planificación urbana (Suyasun, 1997). 
El proceso de desplazamiento conllevó la aparición de organizaciones de desplazados en ciudades de varios departamentos del país. Mientras que las primeras experiencias organizativas se dieron a mediados de la década de 1980 en Huancayo y Lima, para la década de 1990 había bases departamentales con importante vida orgánica en Ica, Apurímac, Huánuco, Ayacucho y Huancavelica (Paz Ruiz, 2004). De entre los países latinoamericanos con presencia de población desplazada, el Perú fue en su momento motivo de sorpresa en cuanto al nivel de organización, al punto que, en 1995, el representante del secretario general de las Naciones Unidas sobre los Derechos Humanos de los Desplazados Internos señaló que aquí «los desplazados están organizados en una medida que [...] no había visto en ningún otro país. A todos los niveles hay organizaciones que velan por los intereses de los desplazados, los retornados y los que han optado por un asentamiento diferente» (Deng [1996] 2010, p. 243).

La impresión no era gratuita. El movimiento organizado de los desplazados logró alcanzar dimensiones significativas. En 1996, las distintas bases regionales lograron unificar intereses, y en un congreso nacional que contó con la presencia de 350 delegados de todo el país, se formó la Coordinadora Nacional de Desplazados y Comunidades en Reconstrucción del Perú (Condecorep), que según un cálculo habría agrupado a 45000 personas pertenecientes a 9000 familias (Cohen y Sánchez-Garzoli, 2001, p. 12), y cuya trayectoria ha sido plasmada en un libro producido desde su propia experiencia (Condecorep, 2004).

A tres décadas de las primeras experiencias de organización de desplazados por el conflicto armado, esta solidez organizativa descrita en su momento parece haberse perdido, si es que alguna vez existió. Diversos factores habrían participado de este debilitamiento: la ausencia de un compromiso de la comunidad de derechos humanos con el tema de desplazados (Paz Ruiz, 2004, p. 13), el «agotamiento del ciclo de las ayudas a desplazados desde las ONG» (Diez Hurtado, 2003, p. 27), capacidades insuficientes de gestión y liderazgo (Quispe Córdova, Humaní Palomino, Huamán Ramos y Choquecahua, 2013), entre otros elementos. Por su parte, para Bebbington, Scurrah y Bielich (2011) existe una debilidad general en el conjunto de organizaciones de afectados por el conflicto armado, debido a su renuencia a identificarse como víctimas (por la estigmatización que esto conlleva), los pocos recursos económicos con los que cuentan sus miembros y la desconfianza entre organizaciones que tienes distintas maneras de autopercibirse en razón de haber sufrido diferentes tipos de afectación (víctimas de Sendero Luminoso, víctimas de la Fuerzas Armadas, familiares de personas asesinadas / desaparecidas, desplazados, etc.). Esta realidad, a su vez, puede entenderse en 
relación con un proceso de debilitamiento general de las articulaciones sociales y políticas que se hace notorio a partir de la década de 1990 (Tanaka, 1998).

Así, la bibliografía muestra que la población desplazada en las ciudades reside en espacios urbanos periféricos, está débilmente articulada a las principales dinámicas económicas de las ciudades ${ }^{10} \mathrm{y}$ carece de solidez orgánica. Sin embargo, carecer de solidez orgánica no implica una ausencia de vida orgánica: hasta mediados de 2014, el Libro 2 tenía registrados a 46 grupos de desplazados, en tanto que un año antes el MIMP calculaba que en todo el país existían 192 organizaciones de desplazados (Comisión Multisectorial de Alto Nivel Encargada de las Acciones y Políticas del Estado en los Ámbitos de la Paz, la Reparación Colectiva y la Reconciliación Nacional, 2013, p. 5). Hay, pues, un número importante de desplazados agrupados que tendrían la expectativa de reclamar los derechos que les corresponden como beneficiarios colectivos en el marco del PIR.

En relación con la política estatal de reparaciones, algunas publicaciones han acusado su desarticulación e ineficiencia. Específicamente, encuentran ausencia de integralidad en la implementación (Correa, 2013), deficiencias normativas y de diseño institucional, así como ausencia de mecanismos de evaluación y monitoreo (Defensoría del Pueblo, 2013), insuficiente capacidad instalada para la implementación de reparaciones regionales (Barrenechea, 2010) y, para el caso de algunas comunidades rurales en Ayacucho, una población local que percibe las reparaciones no como restitución de derechos sino como programas estatales de asistencia social (Ulfe, 2013). Para el caso de las personas desplazadas, se ha señalado que estas se encuentran relegadas en materia de atención y reparación respecto de quienes sufrieron formas de afectación ligadas a la violación de derechos civiles y políticos (desaparición, tortura, etc.) (Barrantes, 2012). Se trata, en suma, de textos que analizan la oferta estatal de reparaciones y señalan su baja calidad.

Esta investigación, por su parte, realiza una aproximación etnográfica para explorar la «demanda», y la capacidad de esta demanda para recibir la oferta en condiciones auspiciosas. Así, parto de preguntarme por las características de determinados grupos de desplazados beneficiarios de reparaciones colectivas y su relación con el acceso a dichas reparaciones.

10 La idea de población desplazada que vive en espacios urbanos y periféricos y con débil articulación económica a las ciudades es bastante esquemática. Se requieren estudios que permitan describir y analizar las relaciones concretas detrás de dicha imagen, ya sea para reafirmarla, matizarla o cuestionarla. 


\section{CARACTERIZACIÓN DE DOS ORGANIZACIONES DE DESPLAZADOS EN LIMA}

Este apartado describe y analiza las principales características de dos organizaciones de desplazados en Lima respecto de sus obstáculos o facilidades para acceder a atención y reparaciones.

La primera de ellas está formalmente inscrita en el Libro 2 del RUV como «Asociación de Familias Desplazadas de la Comunidad de Cochatay Sector Huachipa - Chosica» (me referiré a ella como «Cochatay»). Está ubicada en Cajamarquilla - Huachipa, distrito de Lurigancho, Chosica. La segunda responde al nombre de «Asociación de Víctimas de la Violencia Política Sumaq Qoyllor Huaycán» (me referiré a ella como «Sumaq Qoyllor») y tiene su lugar de residencia en Huaycán, distrito de Ate ${ }^{11}$.

Cochatay está conformada fundamentalmente por hombres y mujeres provenientes de la comunidad de Cochatay, en el distrito de Cangallo, Ayacucho. Los vínculos familiares entre los miembros son bastante densos: apellidos como Sulca, Pablo y Quique son recurrentes. Se trata de lo que se denomina «agrupación por lugar de origen», es decir, una agrupación formada por quienes tienen un mismo origen geográfico.

Sumaq Qoyllor es una agrupación conformada exclusivamente por mujeres desplazadas provenientes de distintas regiones de la sierra (Ayacucho, Huancavelica, Junín, etc.). Por eso mismo, los vínculos familiares entre ellas no son tan densos como en el caso anterior. Se trata de lo que se denomina «agrupación por lugar de refugio» ${ }^{12}$, es decir, una agrupación formada por personas con distintos orígenes geográficos, pero que viven en una misma zona de la ciudad.

Uno de los antecedentes históricos más importantes de Cochatay refiere a la larga tradición de trabajo informal en ladrilleras. Desde muy temprano, a mediados de la década de 1980, un porcentaje importante de hombres de Cochatay ha trabajado - y sigue trabajando - en la fabricación y transporte de ladrillos. Huachipa, de hecho, es una zona de la ciudad en donde la presencia de fábricas y hornos de ladrillos es significativa, y que fue referida en un informe

11 Por razones de confidencialidad, he modificado ligeramente los nombres de estas asociaciones. Asimismo, para el primer caso he inventado un nombre falso para el lugar de origen de los miembros de su organización.

12 Las expresiones "lugar de origen" y "lugar de refugio" son tomadas de la siguiente frase: "Nuestras bases están organizadas por lugar de origen y por lugar de refugio, en ambos casos participan de las decisiones de la organización a través de sus delegados" (Coordinadora Nacional de Desplazados y Comunidades en Reconstrucción del Perú 2011, p. 30). 
internacional sobre desplazados como un lugar donde el trabajo es «demoledor, mal pagado e inseguro» y en donde se acusa «casi total carencia de estándares mínimos aceptables de vida» (Misión ICVA, 1997, p. 228). Varios entrevistados para este trabajo refieren no solo haber trabajado en ladrillerías, sino también haber vivido dentro de estas por muchos años antes de residir en los lotes que ocupan ahora. Este antecedente es importante de cara a la reparación colectiva, como veremos más adelante.

Muchas de las señoras que fundaron Sumaq Qoylllor, por su parte, llegan primero a la zona de Vitarte, donde fueron acogidas por la iglesia (católica) de la zona, que les brindó asistencia humanitaria: colchas, alimento, techo. El vínculo con la iglesia continúa hasta hoy: la asociación Sumaq Qoyllor se reúne semanalmente alrededor de las tres de la tarde en un comedor zonal que es, a la vez, capilla. En efecto, el comedor pertenece a la parroquia de Huaycán, entidad que presta el local desde hace varios años a la asociación para que se reúna allí. Asimismo, la principal asesora de Sumaq Qoyllor es una agente pastoral que participa de la comunidad institucional de derechos humanos en Lima. Esto nos lleva al tercer punto en esta descripción: los vínculos de las asociaciones con actores externos.

La principal asesora de Sumaq Qoyllor es una religiosa italiana que llegó al Perú en la década de 1990. Casi desde los inicios, trabajó con la iglesia de Vitarte. Dada la cercanía geográfica y el interés de ella por temas de derechos humanos y justicia social, fue inevitable su acercamiento con quienes sufrían problemas derivados del conflicto armado. En la práctica, sin embargo, ella es más que una asesora. Por ejemplo, muchas reuniones de Sumaq Qoyllor empiezan cuando ella llega, y a veces — no siempre - terminan cuando se va. Puede ocurrir que, si alguna socia tiene que abandonar temprano una reunión, le pida permiso a ella para retirarse y no a la presidenta de la organización. Así, al menos para ciertos temas, hay una suerte de dependencia del grupo respecto de su asesora. No es para menos: ella es, por ejemplo, quien aclara dudas sobre en qué consisten las reparaciones, es quien ha contactado a algunas personas para hacer talleres de tejido o manualidades — en lo cual se han especializado-, y quien en algunas ocasiones aporta económicamente para el pasaje de las dirigentes. Algunas de las señoras entrevistadas han llegado a decir que quizás la organización ya no existiría de no ser por ella.

Sumaq Qoyllor mantiene vínculos con la Coordinadora Nacional de Afectados por la Violencia Política (Conavip). Esta es una organización paraguas de alcance nacional que agrupa a organizaciones regionales y locales que se identifican con 
distintas formas de afectación respectivamente (viudas de la Policía Nacional, familiares de personas desaparecidas, desplazados, etc.). En ese sentido, Sumaq Qoyllor es una «base» de Conavip. Las principales demandas de Conavip se relacionan con las víctimas mortales del conflicto, como el establecer una política de búsqueda de personas desaparecidas y el pago de reparaciones económicas. Varios entrevistados señalan que, si bien en sus reuniones se habla sobre reparaciones a desplazados, estas no son el tema central de sus discusiones ${ }^{13}$. Aun así, al menos desde el año 2015 las principales dirigentes de Sumaq Qoyllor han acudido a distintas reuniones y actividades que Conavip ha convocado, quizás porque ven en ella fortalezas colectivas que eventualmente pueden beneficiarlas.

Cochatay, por su parte, está articulada a la Condecorep, ya anteriormente mencionada. Esta es también una organización paraguas de alcance nacional. Así, Cochatay es una «base» de Condecorep, organización en cuya agenda las demandas y problemas ligados específicamente al desplazamiento (que no es una forma de victimización mortal) ocupan un lugar central.

La relación de las bases con las organizaciones paraguas también es diferente en cada caso. Mientras que las dirigentes de Sumaq Qoyllor responden la mayoría de las veces a las convocatorias que realiza el presidente de Conavip, la actual dirigencia de Cochatay tiene relaciones conflictivas con el presidente de Condecorep, al cual hacen responsable de una mala gestión en asuntos de orden práctico. En este aspecto, la principal crítica tiene que ver con la demora de tres años que tomó la regularización de su estatuto, de lo cual hacen responsable al referido dirigente; además, su trato estrecho con los especialistas de la Dirección de Desplazados los hace sospechar que él tiene algún acuerdo monetario con ellos. Se trata de un caso en el cual la imagen del dirigente nacional se ve mellada por su incapacidad de cumplir con requisitos burocráticos, aspecto que se suma a algunos antecedentes negativos, como el fracaso en las negociaciones de un proyecto previo de reparación colectiva ${ }^{14}$. La conjunción de estos eventos ha hecho del perfil político de esta persona, marcado por casi tres décadas como dirigente de desplazados, una característica que despierta sospecha («además, tú

13 Parece tratarse de un patrón que se repite en otras regiones. Para el caso ayacuchano, una investigación encuentra que los grupos de desplazados se sienten utilizados por la base regional de Conavip, a la que acusan de no atender sus demandas (Quispe Córdova, Humaní Palomino, Huamán Ramos y Choquecahua, 2013, p. 109). Si bien puede tratarse de una acusación injusta, da cuenta de cierta dificultad para integrar el desplazamiento como una afectación en la agenda principal de demandas de atención y reparación.

14 El entusiasmo que la posibilidad de concretar dicho proyecto despertó en su momento ha sido narrado por Agüero (2011). 
sabes que él es político y tiene sus propios intereses»). Es así que, por más de un año, el presidente de Condecorep no ha asistido a reunión alguna en Cochatay.

Por casi seis años, Sumaq Qoyllor tuvo como presidenta a una misma socia. Se trata de una mujer huancavelicana que desde que llegó a Huaycán, en la década de 1980, tuvo roles dirigenciales. Según la agente pastoral, se trata de la única socia de Sumaq Qoyllor que realmente pudo desarrollar un liderazgo fuerte. Desde 2013, esta señora no solo no es presidenta de la asociación, sino que se ha alejado de ella por completo. A las interpretaciones de este alejamiento que tienen las socias de Sumaq Qoyllor subyace un hecho cierto: su expresidenta está dirigiendo una ocupación de terrenos en otra zona de Huaycán. Varias versiones se han desprendido de esto: la interpretación crítica, que es la que goza de mayor consenso, dice que esta actividad le genera más ganancias económicas; una interpretación contraria dice que el grueso de socias de la organización se está olvidando que, de no ser por ella, Sumaq Qoyllor no se habría consolidado. Además, se afirma que estas ocupaciones de terrenos estaban pensadas como una ocupación para hijos de desplazados que eventualmente podría haber beneficiado a más socias de Sumaq Qoyllor. En efecto, varios de los participantes de estas invasiones serían desplazados que también viven en Huaycán. A las críticas que esta señora recibe se suma el hecho de que cuando fue presidenta no habría gestionado adecuadamente la documentación de ciertas socias — según algunos testimonios - que se sintieron defraudadas por ella. Dos elementos se han juntado aquí otra vez: la figura de la dirigente histórica percibida como ineficaz en términos de gestión burocrática, lo que lleva a un detrimento de su legitimidad, y la sospecha de un ejercicio político poco transparente, en este caso, como protagonista de ocupaciones de terrenos. Se trata de un problema similar al de Cochatay, con la diferencia de que aquel grupo rompió con un dirigente nacional, mientras que Sumaq Qoyllor rompió con su antigua dirigente de base.

Un último elemento a destacar es el de las relaciones internas. Cochatay es una organización atravesada por distintos conflictos, muchos de los cuales son relativos a su propia dinámica orgánica. Circulan muchos rumores sobre malos manejos económicos de dirigencias anteriores, rumores que alcanzan incluso décadas pasadas y refieren a distintos bienes materiales que habrían llegado a Cochatay gracias a entidades de asistencia social, y de los cuales se habrían apropiado antiguos dirigentes. Al ser Cochatay una agrupación por lugar de origen, sus miembros se conocen desde hace muchos años y las antiguas desconfianzas permanecen. Asimismo, en varias reuniones a las que asistí, diversos socios mostraban su malestar al no encontrarse en el acta de socios inscritos en el Libro 2, 
situación en la cual estaba incluso su principal dirigente en aquel momento. A esto se superpuso la ya mencionada ruptura con el presidente de Condecorep, lo que terminó por desbaratar cualquier liderazgo y paralizar la actividad del grupo.

Internamente, en Sumaq Qoyllor se da una serie de roces e impases referidos a las críticas que las socias se hacen entre sí respecto de su voluntad y disposición a formar parte de las actividades grupales. A pesar de ello, la agente pastoral parece ser un elemento de cohesión que evita que las tensiones internas estallen. Su presencia constante, su contacto con personas externas que brindan talleres y capacitaciones y su colaboración económica ocasional la dotan de funcionalidad práctica para los intereses de la asociación.

Resumamos lo dicho hasta acá. De Cochatay tenemos lo siguiente: a) «agrupación por lugar de origen», b) tradición de trabajo en ladrillería, c) no hay vínculos con asesores externos, d) son parte de Condecorep, pero el vínculo con esta se ha roto, e) vida orgánica debilitada y ausencia de liderazgos. Por su parte, Sumaq Qoyllor presenta las siguientes características: a) «agrupación por lugar de refugio», b) especialización en tejido, c) estrecha relación con la iglesia y vínculo fuerte con una agente pastoral (que a veces parece una suerte de dirigente de facto), d) forman parte de Conavip, con quien actualmente tienen un vínculo sólido, e) cohesión relativamente estable y liderazgo externo de la agente pastoral.

Un aspecto común es el descontento hacia los dirigentes más antiguos con liderazgos fuertes. En el caso de Sumaq Qoyllor, el perjuicio que pudo ocasionar el distanciamiento de su antigua presidenta ha sido menguado por la presencia de la agente pastoral y el vínculo con Conavip. En el caso de Cochatay, no cuentan con ninguna figura que suplante la labor de dirección y asesoramiento que ejercía el presidente de Condecorep, por lo que dependen de ellos mismos para poder sacar adelante las atenciones y proyectos que les interesan. Esto último pone, en principio, a Sumaq Qoyllor en mejor situación de cara a afrontar las reparaciones, en tanto que el hecho de contar con el apoyo de su referida asesora supone una ventaja comparativa.

\section{ORGANIZACIONES DE DESPLAZADOS Y REPARACIONES COLECTIVAS}

Uno de los siete programas de reparación contemplados en el PIR es el Programa de Reparaciones Colectivas. Consiste en concretar un proyecto por un valor máximo de hasta 100000 soles, cuyos beneficiarios son de dos tipos: (i) comunidades andinas y amazónicas que sufrieron los impactos de la violencia, 
y (ii) grupos de desplazados no retornantes, es decir, conformados por personas desplazadas que no hayan vuelto al lugar en el que residían cuando el conflicto estalló. Si bien este artículo se centra en el segundo tipo de beneficiario, viene al caso mencionar dos cosas sobre las reparaciones colectivas en general.

Primero, las reparaciones colectivas empezaron a implementarse en el año 2007 y fueron dirigidas únicamente al primer grupo de beneficiarios, en tanto que recién en el año 2013 se aprobaron los lineamientos para entregar reparaciones colectivas a los grupos de desplazados no retornantes. El desplazamiento, pues, ha sido una prioridad secundaria en lo referente a reparaciones colectivas en el marco de la implementación del PIR. Esto, sumado a la no centralidad de las demandas de los desplazados en las movilizaciones y reuniones de Conavip, refuerza lo señalado al final del tercer apartado respecto del lugar lateral que ocupa el desplazamiento en la agenda global de atención y reparación a los afectados.

En segundo lugar, la experiencia de las reparaciones colectivas en comunidades andinas y amazónicas ha transcurrido con altibajos. Una encuesta hecha a quince centros poblados en seis departamentos del Perú encuentra una percepción general de que estos proyectos benefician a las comunidades, pero también registra que más del $40 \%$ de personas encuestadas —o sus familias-no han podido utilizar el proyecto, y que el $44 \%$ de personas encuestadas califica el proyecto de «bueno» o «muy bueno», mientras que el resto lo evalúa como «regular»o «peor». Por estas y otras razones, el documento concluye que las reparaciones colectivas cumplen su objetivo solo parcialmente (Asociación Pro Derechos Humanos y Centro Internacional para la Justicia Transicional, 2012). Un trabajo etnográfico en once comunidades ayacuchanas encuentra también un descontento acentuado con la implementación de reparaciones colectivas y expectativas defraudadas respecto del progreso económico que estas podrían haber impulsado (Bunselmeyer, 2017).

Otro informe (Defensoría del Pueblo, 2013) identifica como problemas principales el desconocimiento de los comités de gestión de los contenidos de los expedientes técnicos, abandonos de las obras sin explicación, autoridades locales que hacen cobros indebidos, poca participación de las mujeres y escasa prioridad dada a los afectados en la contratación de mano de obra no calificada, lo cual atentaría contra la sostenibilidad de estos proyectos.

Desde su propia experiencia, la Coordinadora Nacional de Desplazados y Comunidades en Reconstrucción del Perú (2011) llegó a afirmar que las reparaciones no se han diseñado para proveer información adecuada, flexibilidad, adaptabilidad y acceso efectivo a los desplazados, y en relación con las 
reparaciones colectivas, identificó como un obstáculo importante que la CMAN no contase en su momento con mecanismos de apoyo técnico para que los desplazados diseñen y presenten sus proyectos.

Lo dicho permite afirmar que existe ya evidencia acumulada respecto de una serie de problemas que se han presentado en la implementación de reparaciones colectivas para el primer tipo de beneficiarios ${ }^{15}$, así como una crítica desde Condecorep a la manera en que se repara a los desplazados. Como veremos a continuación, se presentan también problemas para los grupos de desplazado beneficiarios en el acceso a la reparación colectiva, que puede atentar contra los objetivos de esta.

Según los lineamientos para implementar reparaciones colectivas a organizaciones de desplazados internos no retornantes, los proyectos de reparación colectiva tienen como fin «contribuir a la reconstrucción del capital social, institucional, material y económico de las familias desplazadas» (Comisión Multisectorial de Alto Nivel Encargada de las Acciones y Políticas del Estado en los Ámbitos de la Paz, la Reparación Colectiva y la Reconciliación Nacional, 2013, p. 7) y pueden concretarse en aspectos tan diversos como apoyo a saneamiento físico legal, capacitación en derechos humanos, ampliación de infraestructura y servicios básicos, proyectos productivos y de comercio, entre otros. ¿Cómo es que los grupos de desplazados encaran la posibilidad de acceder a esta forma de reparación?

Recordemos que en Cochatay hay una tradición de trabajo informal en ladrillería. Cuando diseñaron su proyecto de reparación colectiva, en el año 2014, acordaron que esta se concrete en un proyecto productivo de fabricación de ladrillos. La idea, sin embargo, fue desechada. En tanto que la reparación colectiva es un proyecto avalado por el Estado, esta debe incluir costos asociados a seguridad, pago de impuestos y condiciones laborales adecuadas, costos que no existen en ambientes laborales informales. Al hacer los cálculos correspondientes, conjuntamente con los técnicos de la Dirección de Desplazados, encontraron que un proyecto de este tipo, con todos esos gastos incluidos, no resultaba rentable. Esto es interesante porque muestra no solo la importancia de la historia grupal para comprender sus decisiones en materia de proyectos de reparación sino, además, cómo los requisitos de la burocracia estatal entran en conflicto con la historia laboral local. Ante esta situación, Cochatay decidió cambiar su proyecto y propuso hacer un local comunal.

15 La mayoría de dicha evidencia corresponde a la situación de hace cinco años. Se necesitan nuevas investigaciones sobre el particular. 
Esto también tiene una explicación. Cochatay está en una zona rodeada de fábricas de cemento, leche y ladrillos y más de una vez les han ofrecido ayuda con materiales, chocolatadas y demás favores, pero siempre con la condición de tener un local comunal. No solo se trata, pues, de la necesidad de contar con un lugar en el cual reunirse, sino también de aprovechar una oportunidad en función de posibles beneficios materiales proveídos por terceros. Sin embargo, suspendida la relación con el presidente de Condecorep — quien servía de vínculo efectivo con los técnicos de la Dirección de Desplazados e informaba sobre los avances y noticias en materia de reparación y atención-, la base ha perdido dinamismo y actividad.

Sumaq Qoyllor, por su parte, no necesita de local comunal: usa el que le presta la iglesia, que es a la vez capilla y comedor popular. Ellas están esperando la implementación un proyecto empresarial de producción de tejidos. Es una elección esperable, pues Sumaq Qoyllor tiene una tradición de trabajo en arpillería y ha elaborado piezas que se han mostrado en diversas exposiciones, dentro y fuera del Perú. No obstante haber perdido el fuerte liderazgo de su ex presidenta, sus vínculos con Conavip y la presencia de la agente pastoral potencian su vida orgánica y le han permitido avanzar de forma significativa en el proceso de acceder a reparaciones colectivas. Aquí, sin embargo, aparece otro actor: el gobierno municipal.

Según el reglamento existente, es el municipio el que tiene que diseñar y ejecutar el proyecto de reparación colectiva. En este punto se está presentando una serie de dificultades administrativas cuya enumeración escapa a los propósitos de este artículo. Me interesa, más bien, señalar que un temor presente entre las socias de Sumaq Qoyllor es el de no estar listas para recibir el proyecto y sostenerlo. Entre otras razones, esto se debe a su edad avanzada y a la posibilidad de no tener ni el tiempo ni la energía suficientes para el trabajo requerido. Por otra parte, hay casi setenta miembros en la organización, por lo que aún es un tema pendiente saber cómo resolver la tensión entre derecho (es decir, que el proyecto debe beneficiar a todas) y participación efectiva (es decir, atender el reclamo legítimo de que quienes dediquen más tiempo a trabajar en él deben recibir mayores beneficios). La gran mayoría son iletradas, por lo que dudan sobre su preparación para asumir tareas complejas, como contabilidad y rendición de cuentas. Así, parece que los potenciales problemas que la reparación colectiva puede traer a Sumaq Qoyllor son mayores que aquellos que el local comunal puede traer a Cochatay, pues en este último no hay ganancia de dinero $u$ oportunidades laborales en juego ${ }^{16}$.

16 Las descripciones de este apartado y el anterior corresponden a la situación de ambos grupos hasta mediados del año 2016, cuando culminó el trabajo de campo. Al día de hoy, Sumaq 


\section{CONCLUSIONES}

La investigación presentada en este artículo muestra que los antecedentes laborales o técnicos de los grupos de desplazados son importantes para determinar, al menos en estos dos casos, la elección del tipo de reparación colectiva a elegir. Sin embargo, variables como el grado de formalidad de estos antecedentes y el nivel de solidez orgánica de la asociación son aspectos importantes que pueden condicionar el buen o mal funcionamiento de estos proyectos. Dicho de otra forma, las características de cada organización, junto con el tipo de proyecto de reparación escogido, crean escenarios de retos y posibilidades cuya resolución muchas veces está lejos de ser clara. Sumaq Qoyllor tiene aliados más calificados que Cochatay y una cohesión interna relativamente estable, lo que le ha permitido lograr la aprobación su proyecto de reparación colectiva y avanzar en su implementación. Sin embargo, al tratarse de un proyecto productivo, enfrenta una serie de requerimientos y tensiones referidos a su sostenibilidad respecto de los cuales las socias están en una situación de incertidumbre. Por su parte, si bien Cochatay no tiene el nivel de avance de la primera asociación, lo cierto es que en un eventual escenario de implementación del local comunal no parece que fueran a encontrarse dificultades como las del caso anterior, aunque sí podría especularse sobre posibles conflictos alrededor de las futuras donaciones y favores que presten las empresas de la zona.

Estos hallazgos permiten afirmar que los desafíos que enfrenta la implementación de las reparaciones tienen un componente importante en la calidad de la «oferta», pero es también oportuno conocer el estado de la «demanda» - es decir, de la estructura de relaciones sociales de los grupos de desplazados beneficiarios - para comprender sus posibilidades de acceso a reparaciones. Un elemento de estas relaciones gira en torno a las características de los liderazgos de cada asociación. Los dos grupos analizados rompieron con dirigentes más antiguos, pero mientras uno carece de liderazgos internos debido a sus propios conflictos, el otro se sostiene en la presencia de una asesora externa que cohesiona a la asociación.

Qoyllor ha recibido ya su proyecto de reparación colectiva, pero aún no es posible evaluar su éxito o fracaso. Algunas socias con las que he conversado de manera informal señalan que varias de ellas no están del todo satisfechas con el resultado. Por lo demás, mantienen el vínculo con la agente pastoral. Ahora tienen sus reuniones semanales en el local donde está ubicado el proyecto de reparación, pero siguen usando el comedor de la iglesia. Por su parte, algunos miembros de la asociación de Cochatay han retomado el contacto con el presidente de Condecorep, pero aún no logran concretar la aprobación de un proyecto de reparación colectiva. 
Una hipótesis a trabajar más adelante tiene que ver con la funcionalidad de los dirigentes históricos de las organizaciones de afectados ante contextos cambiantes. Parece que estos liderazgos se mantienen sólidos cuando aún no hay lineamientos ni autorización para el desarrollo de determinados programas de reparación; en estos casos, las capacidades para exigir, criticar y demandar son valoradas y efectivamente ejercidas. No obstante, una vez que estos programas de reparación comienzan a implementarse, resulta más difícil mantener el mismo nivel de legitimidad de los liderazgos, porque se entra a una fase en donde se debe lidiar con burocracias y procedimientos técnicos para los cuales estos líderes están menos preparados, por lo que se les hace más difícil obtener resultados y comienzan a perder prestigio.

Una segunda hipótesis, derivada de lo anterior, apunta a una serie de problemas en el cuerpo social que el conflicto armado, o bien creó, o bien potenció, y que las reparaciones no están abordando (no queda claro si les corresponde abordarlos). Uno de ellos es el debilitamiento del tejido político: la pérdida de una o dos generaciones de líderes políticos campesinos. Muchos de los que sobrevivieron se dispersaron en ciudades a causa del conflicto armado, en donde encuentran dificultades para continuar con actividades dirigenciales, lo que deriva en asociaciones débiles, en conflicto o con poca capacidad para incidir en los procesos que les interesan.

La discusión en torno a las reparaciones derivadas de los daños del conflicto armado pone un fuerte énfasis en el derecho que asiste a los afectados por acceder a estas. Para el caso del Programa de Reparaciones Colectivas - y en particular, aquellas reparaciones dirigidas a grupos de desplazados no retornantes-, el acceso al derecho está condicionado, en los hechos, a que dichos grupos logren desplegar una acción colectiva sólida, capaz de lidiar con procedimientos burocráticos, distintos actores estatales, y de mantener a la par la estabilidad interna. Es decir, en los casos vistos, el acceso efectivo a un derecho (el de reparaciones colectivas) se encuentra en el camino con los costos de dinero, tiempo y oportunidad implicados en la acción grupal necesaria para dicho acceso, y su resolución se le carga enteramente a la asociación beneficiaria.

Se desprenden de esto algunas preguntas que pueden orientar futuras reflexiones. ¿Qué ocurre con este derecho cuando dichos costos superan la capacidad grupal de acción? Si esto es así, ¿podemos, entonces, decir que estamos ante un derecho cuyo cumplimiento no está garantizado? Y en ese caso, ¿debería haber alguna consideración sobre la pertinencia moral de exigir cierto tipo de requisitos a un grupo de personas para acceder a determinado derecho? Sean cuales fueren 
las respuestas, o sea que haya mejores preguntas a formular, lo que deja en claro esta etnografía es la necesidad de reducir la brecha que hay entre los requisitos para el acceso a un derecho y las capacidades de los beneficiarios para ello.

\section{REFERENCIAS}

Agüero, José Carlos (2011). Lugares comunes [entrada de blog], 4 de agosto. Disponible en http://negloaguero.blogspot.com/search?q=desplazados. Revisado el 25 de mayo del 2016.

Asociación de Familias Desplazadas en Lima (2009). Atención y reparación para los desplazados en Lima por el proceso de violencia política. Lima: CNDDHH.

Asociación Pro Derechos Humanos y Centro Internacional para la Justicia Transicional (2012). ¿Cuánto se ha reparado en nuestras comunidades? Avances, percepciones y recomendaciones sobre reparaciones colectivas en el Perú (2007-2011). Lima: ICTJ.

Barrantes, Rafael (2012). Reparations and Displacement in Peru. Nueva York: ICTJ / Brookings.

Barrenechea, Rodrigo (2010). Política locales de reparación en Ayacucho. ¿Reparaciones sin reparadores? Lima: IEP.

Bebbington, Anthony, Martin Scurrah y Claudia Bielich (2011). Los movimientos sociales y la política de la pobreza en el Perú. Lima: IEP / CEPES / GPC.

Bunselmeyer, Elisabeth (2017). ¿Una vaca = una vida? Reparaciones y desigualdad en comunidades posconflictos del Perú. En Svenja Blanke y Sabine Kurtenbach (eds.), Violencia y desigualdad: ADLAF Congreso 2016 (pp. 52-63). Buenos Aires: Nueva Sociedad/ Friedrich-Ebert-Stiftung.

Cohen, Roberta y Francis M. Deng (2008). Orígenes y desafíos. Revista Migraciones Forzadas, Special Issue: Diez años de los Principios Rectores del Desplazamiento Interno, 4-5.

Cohen, Roberta y Gimena Sánchez-Garzoli (2001). Internal Displacement in the Americas: some distinctive features. Washington DC: Brookings.

Comisión de la Verdad y Reconciliación (2003). Informe Final. Tomo VI. Lima: CVR.

Comisión Multisectorial de Alto Nivel Encargada de las Acciones y Políticas del Estado en los Ámbitos de la Paz, la Reparación Colectiva y la Reconciliación Nacional (2013). Lineamientos para la implementación del programa de reparaciones colectivas para grupos y organizaciones de desplazados internos no retornantes (PRC-D). Lima. 
Coordinadora Nacional de Desplazados y Comunidades en Reconstrucción del Perú (2004). Espejo de la verdad. Memorias para no olvidar, lecciones para la historia. Lima: CONDECOREP.

Coordinadora Nacional de Desplazados y Comunidades en Reconstrucción del Perú (2011). Agenda nacional de las y los desplazados. Propuesta de la CONDECOREP para la reparación integral a las y los desplazados por la violencia política en el Perú. Lima: Condecorep / PCS.

Coral, Isabel (1994). Desplazamiento por violencia política en el Perú. Lima: Instituto de Estudios Peruanos.

Correa, C. (2013). Reparaciones en Perú. El largo camino entre las recomendaciones y la implementación. New York: ICTJ.

Defensoría del Pueblo (2013). A diez años de verdad, justicia y reparación. Avances, retrocesos y desafios de un proceso inconcluso. Lima: Defensoría del Pueblo.

Degregori, C. I. (2011). Introducción. Sendero Luminoso: un objeto de estudio opaco y elusivo. En Qué dificil es ser Dios. El Partido Comunista del Perú - Sendero Luminoso y el conflicto armado interno en el Perú: 1980-1999 [Obras escogidas I] (pp. 17-81). Lima: IEP.

Deng, Francis M. (2010 [1996]). Documento E/CN.4/1996/52/Add.1 del Comisión de Derechos Humanos de las Naciones Unidas. Informe del Representante del Secretario General, Sr. Francis M. Deng, presentado en cumplimiento de la resolución 1995/57 de la Comisión de Derechos Humanos: Estudio de caso de desplazamiento: Perú. En Ministerio de la Mujer y Desarrollo Social, Compendio de normas y documentos sobre desplazamientos internos (pp. 213-254). Lima: Mimdes.

Diez-Hurtado, Alejandro (2003). Los desplazados en el Perú. Lima: Comité Internacional de la Cruz Roja.

Francke, Pedro, Augusto Castro, Marfil Francke y Juanpedro Espino (2001). La experiencia del PAR. Lecciones para redefinir la estrategia de intervención estatal en poblaciones afectadas por la violencia política. Allpanchis XXXI, 58, 3-111.

Internal Displacement Monitoring Centre (2018). GRID 2018. Global Report on Internal Displacement. Geneva: IDMC / NRC.

Mendoza, Juan (2000). Los desplazados. 600,000 ciudadanos peruanos sin derechos. Lima.

Ministerio de la Mujer y Desarrollo Social (2010). Compendio de Normas y Documentos sobre Desplazamientos Internos. Lima: Mimdes. 
Misión ICVA (1997). Informe de la Misión ICVA al Perú. En Instituto de Defensa Legal, Consulta sobre desplazamiento y refugio en la región andina (pp. 221-242). Lima: IDL.

Oficina de Coordinación de Asuntos Humanitarios de las Naciones Unidas (2010). Principios rectores de los desplazamientos internos. En Ministerio de la Mujer y Desarrollo Social, Compendio de normas y documentos sobre desplazamientos internos (pp. 9-21). Lima: MIMDES.

Paz Ruiz, R. (2004). Mapeo de las organizaciones de afectados por la violencia política en el Perú. Lima: Oxfam.

Quispe Córdova, Maricela N., Gloria Huamaní Palomino, Celsa Huamán Ramos y Leonor Choquecahua (2013). Los desplazados en los distritos urbanos de Huamanga. Un diagnóstico. Huamanga: Centro Loyola.

Ramírez Zapata, Ivan (2018). El Registro Nacional para las Personas Desplazadas: características y limitaciones. Revista Mexicana de Sociología, 80(3), 675-702. https://doi.org/10.22201/iis.01882503p.2018.3.57741

Revollar Añaños, Eliana (2001). Los desplazados por violencia política en el Perú. Allpanchis XXXI, 58, 9-31.

Salazar Borja, Gabriel (2015). Sin debates no hay campo. Un acercamiento a los estudios sobre memorias de violencia política en el Perú. En Carlos Iván Degregori, Tamia Portugal Teillier, Gabriel Salazar Borja y Renzo Aroni Sulca (eds.), No hay mañana sin ayer, batallas por la memoria y consolidación democrática en el Perú (pp. 237-301). Lima: IEP.

Stepputat, Finn y Ninna N. Sørensen (2001). The rise and fall of «internally displaced people» in the central Peruvian Andes. Development and Change, 32(4), 769791. https://doi.org/10.1111/1467-7660.00225

Suyasun (1997). Construyendo una esperanza. Lima: Suyasun.

Tanaka, Martín (1998). Los espejismos de la democracia: el colapso de un sistema de partidos en el Perú, 1980-1995, en perspectiva comparada. Lima: IEP.

Ulfe, María Eugenia (2013). ¿Y después de la violencia qué queda? Víctimas, ciudadanos y reparaciones en el contexto post-CVR en el Perú. Buenos Aires: CLACSO.

United Nations High Commissioner for Refugees (2015). Report of Statistics Norway and the Office of the United Nations High Commissioner for Refugees on statistics on refugees and internally displaced persons ( ${ }^{\circ}$ E/CN.3/2015/9). United Nations Economic and Social Council. 